\title{
A bottom-up approach for the synthesis of highly ordered fullerene-intercalated graphene hybrids
}

\author{
Antonios Kouloumpis ${ }^{1}$, Konstantinos Spyrou ${ }^{1,2}$, Konstantinos Dimos ${ }^{1}$, Vasilios Georgakilas ${ }^{3}$, Petra Rudolf ${ }^{2}$ \\ and Dimitrios Gournis ${ }^{1}$ *
}

${ }^{1}$ Department of Materials Science and Engineering, University of loannina, loannina, Greece

2 Zernike Institute for Advanced Materials, University of Groningen, Groningen, Netherlands

${ }^{3}$ Department of Materials Science, University of Patras, Rio, Greece

\section{Edited by:}

Emilia Morallon, Universidad de

Alicante, Spain

Reviewed by:

Junyi Ji, Sichuan University, China

Piotr Gauden, Nicholaus Copernicus

University, Poland

*Correspondence:

Dimitrios Gournis, Department of Materials Science and Engineering,

University of loannina, loannina

45110, Greece

e-mail:dgourni@cc.uoi.gr

\begin{abstract}
Much of the research effort on graphene focuses on its use as a building block for the development of new hybrid nanostructures with well-defined dimensions and properties suitable for applications such as gas storage, heterogeneous catalysis, gas/liquid separations, nanosensing, and biomedicine. Toward this aim, here we describe a new bottom-up approach, which combines self-assembly with the Langmuir-Schaefer deposition technique to synthesize graphene-based layered hybrid materials hosting fullerene molecules within the interlayer space. Our film preparation consists in a bottom-up layer-by-layer process that proceeds via the formation of a hybrid organo-graphene oxide Langmuir film. The structure and composition of these hybrid fullerene-containing thin multilayers deposited on hydrophobic substrates were characterized by a combination of X-ray diffraction, Raman and $X$-ray photoelectron spectroscopies, atomic force and scanning electron microscopies, and conductivity measurements. The latter revealed that the presence of $\mathrm{C}_{60}$ within the interlayer spacing leads to an increase in electrical conductivity of the hybrid material as compared to the organo-graphene matrix alone.
\end{abstract}

Keywords: Langmuir-Blodgett, graphene, fullerene, thin films, hybrids

\section{INTRODUCTION}

The outstanding mechanical, thermal, and electrical properties of graphene have attracted a lot of scientific effort aimed at exploiting them in the development of new hybrid nanostructures with well-defined dimensions and behavior, which contain graphene as building block (Wang et al., 2010; Yin et al., 2012). In fact, graphene sheets can be used as templates for the synthesis of novel intercalated carbon-based materials suitable for various applications in gas storage, gas/liquid separation, heterogeneous catalysis, energy storage, Li-ion batteries, supercapacitors, nanosensing, and biomedicine (Patil et al., 2009; Yu and Dai, 2009; Choi et al., 2010; Wang et al., 2010; Chen et al., 2011; Lei et al., 2011). Combining graphene's properties with the extraordinary properties of fullerenes (Iijima, 1991; Guldi and Prato, 2000) by incorporating the latter into well-defined graphene-based hybrid thin multilayers continues to be a challenging new field for developing novel hybrid nanocomposites.

Toward this aim, here we describe a new bottom-up layer-bylayer approach for the production of graphene hybrid materials where graphene acts as the structure directing interface and reaction media. This method, based on combining self-assembly with the Langmuir-Schaefer (LS) deposition technique, uses the graphene nanosheets as a template for incorporating $\mathrm{C}_{60}$ molecules in a bi-dimensional array, and allows for perfect layer-bylayer growth with control at the molecular level (Gengler et al., 2012a). Similar synthetic protocols have been reported during the last decade for the development of hybrid multilayers and monolayers using the Langmuir-Blodgett (LB) technique. Layered materials like clay minerals (Umemura et al., 2001, 2002, 2009; Yamamoto et al., 2004b; Junxiang et al., 2005; Yoshida et al., 2006; Gengler, 2010; Gengler et al., 2010, 2012a,b; Toma et al., 2010), graphene, and/or graphene oxide (GO) (Cote et al., 2009; Gengler et al., 2010; Zheng et al., 2011b; Michopoulos et al., 2014), or other carbon-based nanostructures (Bourlinos et al., 2012a,b, 2013) have been used to produce hybrid thin multilayers with unique properties. Clay minerals with amphiphilic species and other complexes were combined to fabricate monolayers and multilayers used as photoprobes (Hagerman et al., 2002), sensors (Junxiang et al., 2005), catalysts (Yoshida et al., 2006), and photomagnetic films (Yamamoto et al., 2004a,b). Moreover, the optoelectronic and mechanical properties of graphene can be modified, tuned, or enhanced by layer-by-layer assembly techniques such as the LB method, as has been reported in various studies over the last 3-4 years (for a review, see Kouloumpis et al., 2014). Highperformance dye-sensitized solar cells (Roh et al., 2014) and transparent conductive films (Zheng et al., 2011a) are some examples of the uses of hybrid graphene-based thin multilayers. Finally, the advantages of the precise control and the homogeneous deposition over large areas makes the LB technique promising for preventing carbon-based nanostructures from agglomerating during the film synthesis, as demonstrated for fullerene derivatives or carbon dots (Bourlinos et al., 2012a,b, 2013).

Our film preparation approach involves a bottom-up layer-bylayer process that starts with the formation of a hybrid organographene Langmuir film and proceeds via two self-assembly steps to create a layered structure hosting fullerene molecules within 
its interlayer space (a schematic representation of the synthetic procedure is illustrated in Scheme 1). The composition, structure, and transport properties of the fullerene-containing hybrid thin multilayers deposited on hydrophobic substrates were characterized by X-ray diffraction (XRD), Raman and X-ray photoelectron spectroscopies, atomic force and scanning electron microscopies (SEM), and electrical conductivity measurements.

\section{EXPERIMENTAL SECTION MATERIALS}

Octadecylamine $\left[\mathrm{CH}_{3}\left(\mathrm{CH}_{2}\right)_{17} \mathrm{NH}_{2}, \mathrm{ODA}\right]$, acetone, methanol, and ethanol were purchased from Sigma-Aldrich while fullerene ( $\mathrm{C}_{60}$, powder, 99\% C) was obtained from Alfa Aesar. Ultrapure deionized water (18.2 MOhm) produced by a Millipore Simplicity ${ }^{\circledR}$ system was used throughout. The Si-wafer (P/Bor, single side polished) substrates were cleaned prior to use by $15 \mathrm{~min}$ ultrasonication in water, acetone, and ethanol. All reagents were of analytical grade and were used without further purification.

\section{SYNTHESIS OF GRAPHENE OXIDE}

Graphene oxide was synthesized using a modified Staudenmaier's method (Staudenmaier, 1898; Gengler et al., 2010; Stergiou et al., 2010): $10 \mathrm{~g}$ of powdered graphite (purum, powder $\leq 0.2 \mathrm{~mm}$, Fluka) were added to a mixture of $400 \mathrm{~mL}$ of $95-97 \% \mathrm{H}_{2} \mathrm{SO}_{4}$ (Riedel-de Haën) and $200 \mathrm{~mL}$ of $65 \% \mathrm{HNO}_{3}$ (Fluka), while cooling in an ice-water bath. Two hundred grams of powdered $\mathrm{KClO}_{3}$ (Fluka) were added to the mixture in small portions under vigorous stirring while cooling in the ice-water bath. The reaction was quenched after $18 \mathrm{~h}$ by pouring the mixture into ultrapure water; the oxidation product was washed until the $\mathrm{pH}$ reached 6.0, and finally dried at room temperature.

\section{PREPARATION OF HYBRID GRAPHENE/FULLERENE MULTILAYERS}

A KSV 2000 Nima Technology LB trough was used for the preparation and deposition of multilayers at a temperature of $21 \pm 0.5^{\circ} \mathrm{C}$. The surface pressure in the LB trough was monitored with a Pt Wilhelmy plate. The deposition protocol is schematically illustrated in Scheme 1. A GO suspension in ultrapure water $\left(0.02 \mathrm{mg} \mathrm{mL}^{-1}\right)$ was used as subphase. Two hundred microliters of a $0.2 \mathrm{mg} \mathrm{mL}^{-1}$ ODA solution in chloroform/methanol 9/1 (v/v) were spread onto the water surface using a microsyringe to achieve the hybridization of GO sheets by covalent bonding via the amide functionality. After a waiting time of 20 min to allow for solvent evaporation and GO-surfactant functionalization to occur, the hybrid ODA-GO layer was compressed at a rate of $5 \mathrm{~mm} \mathrm{~min}^{-1}$ until the chosen stabilization pressure of $20 \mathrm{mN} \mathrm{m}^{-1}$ was reached. As in any classical LB experiment, the applied pressure pushes the surfactant molecules along the water surface; the grafted GO sheets will simply follow that movement and therefore become packed, depending on the surface tension established in the trough (Gengler et al., 2010). This pressure was maintained throughout the deposition process. Layers were transferred onto the hydrophobic $\mathrm{Si}$-wafer substrates by horizontal dipping [this way of transferring is known as Langmuir-Schaefer (LS) technique], with downward and lifting speeds of 10 and $5 \mathrm{~mm} \mathrm{~min}^{-1}$, respectively (Cote et al., 2009) - first step in Scheme 1. After the horizontal lift of the substrate, the second step of the deposition protocol consisted in a surface modification of the GO nanosheets, induced by bringing the surface of the transferred Langmuir film (ODA-GO) in contact with a solution of ODA surfactant (self-assembly) dissolved in methanol $\left(0.2 \mathrm{mg} \mathrm{mL}^{-1}\right)$ (Gengler et al., 2010) as illustrated in Scheme 1. In the third and final step, the hybrid organo-GO film was lowered into a solution of $\mathrm{C}_{60}$ in toluene $\left(0.2 \mathrm{mg} \mathrm{mL}^{-1}\right)$

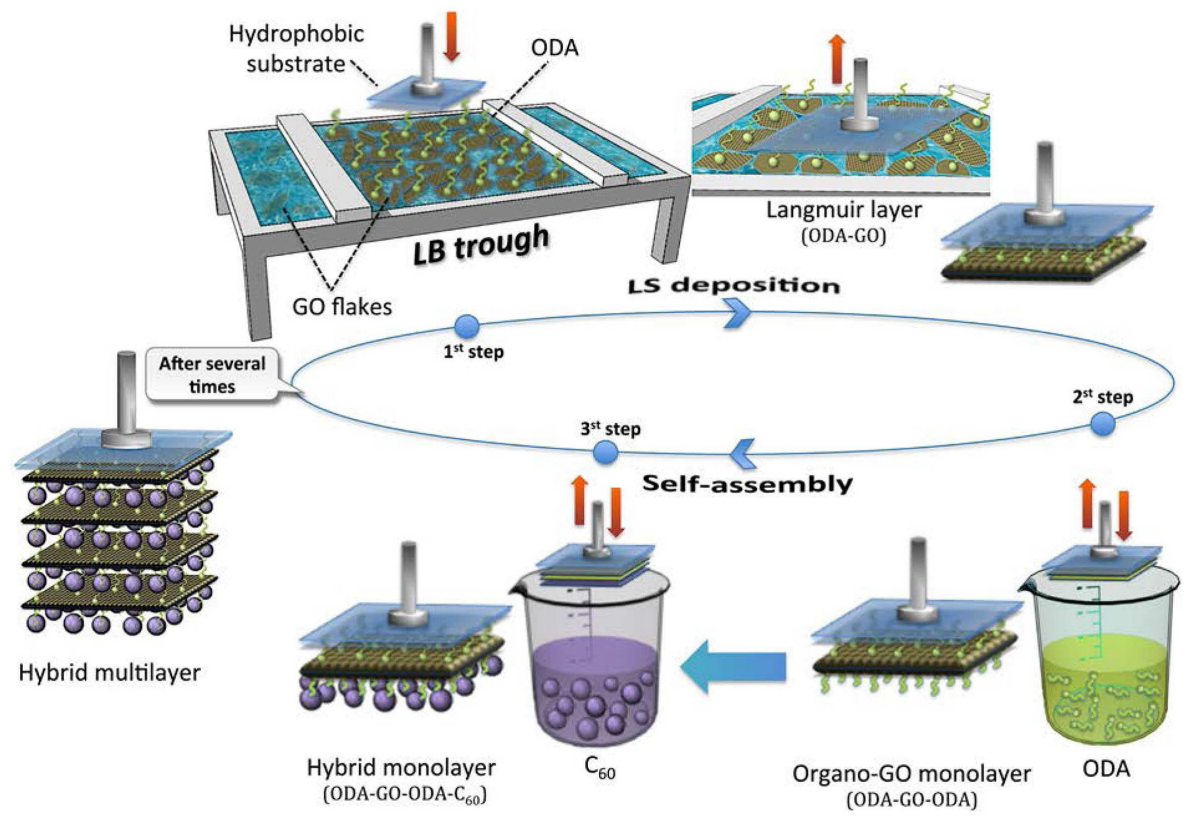

SCHEME 1 | Schematic representation of the synthetic procedure followed for the synthesis of the hybrid $\mathrm{GO} \mathrm{C}_{60}$ multilayer film consisting in a Langmuir-Schaefer deposition (first step) combined with two self-assembly steps (second and third step). 
for the formation of a hybrid graphene/fullerene monolayer by self-assembly. A hybrid multilayer film was constructed by repeating this three-step-dipping cycle 40 times, as shown in Scheme 1 (sample denoted as ODA-GO-ODA- $\mathrm{C}_{60}$ ). Each time when the substrate was lowered toward the liquid surface, it was allowed to touch the air-water interface or the solution surface in a very gentle dip of max $0.5 \mathrm{~mm}$ below the surface for $90 \mathrm{~s}$. After each deposition step, the sample was rinsed several times by dipping into ultrapure water to eliminate any weakly attached molecules that remained from the deposition step and dried with nitrogen flow to avoid contaminating the Langmuir film air-water interface or the solution employed in the following step (Gengler et al., 2012a; Michopoulos et al., 2014). For comparison, an organo-GO hybrid multilayer (40 layers) was also fabricated under the same experimental conditions without the third step of $\mathrm{C}_{60}$ incorporation (sample denoted as ODA-GO-ODA). Moreover, a reduction and an annealing step (fourth step) were also performed in both multilayers in order to convert the deposited GO to graphene and thus to increase the conductivity. For this, the deposited multilayers were immersed into an aqueous solution of $\mathrm{NaBH}_{4}\left(1 \mathrm{mg} \mathrm{mL}^{-1}\right)$ for $10 \mathrm{~min}$ and annealed at $700^{\circ} \mathrm{C}$ for $1 \mathrm{~h}$ under argon (samples denoted as ODArGO-ODA- $\mathrm{C}_{60}$ and ODA-rGO-ODA). This treatment results in a partial reconstruction of the graphene mesh and consequently causes a drastic increase in conductivity (Gengler et al., 2010).

\section{CHARACTERIZATION TECHNIQUES}

Topographic atomic force microscopy (AFM) images were recorded in tapping mode with a Bruker Multimode 3D Nanoscope, using a silicon microfabricated cantilever type TAP-300G, with a tip radius $<10 \mathrm{~nm}$ and force constant range $\sim 20-75 \mathrm{~N} \mathrm{~m}^{-1}$. Raman spectra were collected with a Micro-Raman system RM 1000 RENISHAW using a laser excitation line at $532 \mathrm{~nm}$ (laser diode). A $0.5-1 \mathrm{~mW}$ laser power was used with a $1 \mu \mathrm{m}$ focus spot in order to avoid photodecomposition of the sample. X-ray photoelectron spectroscopy (XPS) measurements were performed in ultrahigh vacuum at a base pressure of $2 \times 10^{-10} \mathrm{mbar}$ with a SPECS GmbH spectrometer equipped with a monochromatic Mg $\mathrm{K} \alpha$ source $(\mathrm{hv}=1253.6 \mathrm{eV})$ and a Phoibos- 100 hemispherical analyzer. The spectra were collected in normal emission and energy resolution was set to $1.16 \mathrm{eV}$ to minimize measuring time. All binding energies were referenced to the $\mathrm{C} 1$ s core level at $285.0 \mathrm{eV}$. Spectral analysis included a Shirley background subtraction and a peak deconvolution employing mixed Gaussian-Lorentzian functions, in a least squares curve-fitting program (WinSpec) developed at the Laboratoire Interdisciplinaire de Spectroscopie Electronique, University of Namur, Belgium. The XRD patterns were collected on a D8 Advance Bruker diffractometer by using a $\mathrm{Cu} \mathrm{K} \alpha$ $(\lambda=1.5418 \AA)$ radiation source $(40 \mathrm{kV}, 40 \mathrm{~mA})$ and a secondary beam graphite monochromator. The patterns were recorded in the 2-theta $(2 \Theta)$ range from 2 to $80^{\circ}$, in steps of $0.02^{\circ}$ and with a counting time of $2 \mathrm{~s}$ per step. SEM images were recorded using a JEOL SEM-6510LV SEM equipped with an EDX analysis system $\mathrm{xx}$-Act from Oxford Instruments. For the electrical conductivity, four-probe measurements were performed using an AFX DC 9660SB power supply and a Keithley 2000 multimeter. Thin films deposited on Si-wafers were measured without any treatment as well as after the reduction and annealing step.

\section{RESULTS AND DISCUSSION STRUCTURE CONTROL OF HYBRID ODA-GO LAYER}

The surface pressure versus molecular area ( $\Pi-\mathrm{a})$ isotherms of ODA monolayers in pure water and on GO dispersion are shown in Figure 1 (right). The curves show the change in the slope corresponding to the phase transitions of ODA-GO sheets from gas to condensed-liquid and then to solid state during the compression process (Michopoulos et al., 2014). In the absence of GO, the $\Pi$-a isotherm is a smoothly increasing curve with a lift-off area of $32.8 \AA^{2}$. When adding a small amount of GO $\left(0.02 \mathrm{mg} \mathrm{mL}^{-1}\right)$ to the aqueous subphase, the lift-off area increased to $52 \AA^{2}$, verifying that GO flakes cause a stabilization effect on the ODA layer (Michopoulos et al., 2014) through chemical grafting (covalent bonding) of the terminal amine groups of ODA to the epoxide groups on the top side of the GO sheets. The amine end groups interact via a ring opening reaction (nucleophilic substitution reactions) of the epoxide groups of GO (Bourlinos et al., 2003; Dreyer et al., 2010; Gengler et al., 2010). At surface pressures above $40 \mathrm{mN} \mathrm{m}^{-1}$, the monolayer collapses due to the formation of bilayers at approximately $26 \AA^{2}$ (Michopoulos et al., 2014).

The successful transfer of the hybrid Langmuir films onto the Si-wafer substrate can be deduced from the plot of the pressure measured at the surface of the subphase in the LB trough versus time (Gengler et al., 2012a). Figure $\mathbf{1}$ (right) shows the time dependence of the total trough area of the hybrid Langmuir film. As the substrate is dipped into the subphase, this area reduces due to the transfer of one hybrid layer from the air-water interface to the substrate during each dip. This transfer is visible as a sharp step in the curve (Toma et al., 2010; Gengler et al., 2012a). If the step height (which gives an area value) is equal to the substrate surface area, the transfer ratio is 1 and the substrate surface is $100 \%$ covered by the hybrid layer each time it is lowered into the subphase. A different transfer ratio suggests a multilayer transfer or an incomplete coverage of the substrate (Gengler et al., 2012a). The curve shown in Figure 1 is a typical one recorded during the deposition of a 10-layer hybrid ODA-GO-ODA- $\mathrm{C}_{60}$ film. The transfer ratio was very close to 1 throughout the deposition, testifying to the successful transfer of the hybrid Langmuir film at each dip of substrate into the LB trough.

Representative AFM images of hybrid GO sheets (ODA-GO) deposited on Si-wafer with the LS method (at surface pressure $20 \mathrm{mN} \mathrm{m}^{-1}$ ) during the first dip into the LB trough (first step in Scheme 1) are shown in Figure 2. In these images, one recognizes high quality GO flakes with well-defined edges and a relatively low amount of cracks and wrinkles. The surface coverage is quite high; the GO platelets in the transferred layer are contacting each other, with hardly any overlap but only small voids between them, forming a nearly continuous, close-packed array. Because of the ODA layer below the GO sheet, the average height of the flakes of $0.9-1.5 \mathrm{~nm}$, as derived from topographical height profile, is larger than the value of $0.61 \mathrm{~nm}$ predicted for a single GO layer (Dekany et al., 1998). However, it is difficult to conclude anything on the orientation of the ODA molecules (straight or inclined) from these images because the height of single GO layers without ODA has also been reported in the literature to be larger than $0.61 \mathrm{~nm}$, namely of the order of $1.1 \pm 0.2 \mathrm{~nm}$ [see, for example, Schniepp et al. (2006) and 


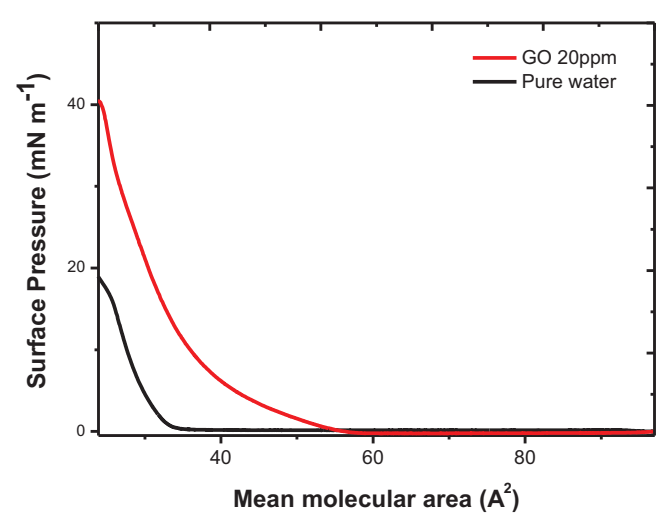

FIGURE 1 | (Left panel) П-a isotherms of ODA monolayers in pure water and on an aqueous dispersion of $0.02 \mathrm{mg} \mathrm{mL}^{-1} \mathrm{GO}$. (Right panel) The black curve corresponds to the trough area covered by the hybrid ODA-GO Langmuir film

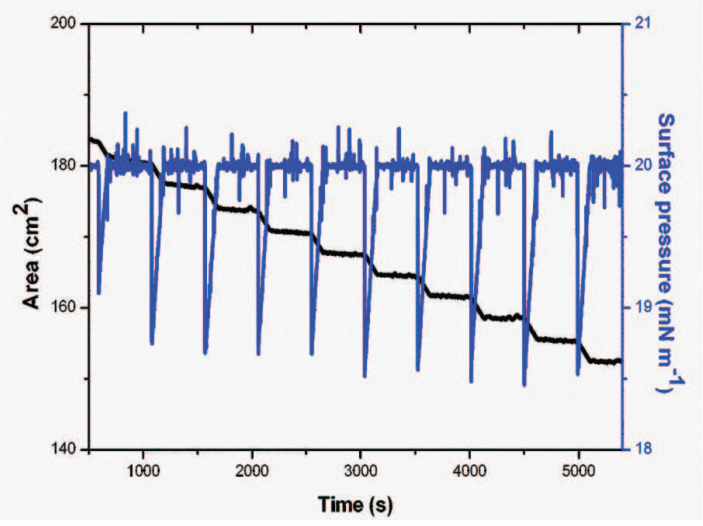

at the air-water surface, and the blue curve shows the surface pressure throughout (around $20 \mathrm{mN} \mathrm{m}^{-1}$ ) the deposition of a 10-layer ODA-GO-ODA-C 60 hybrid film.
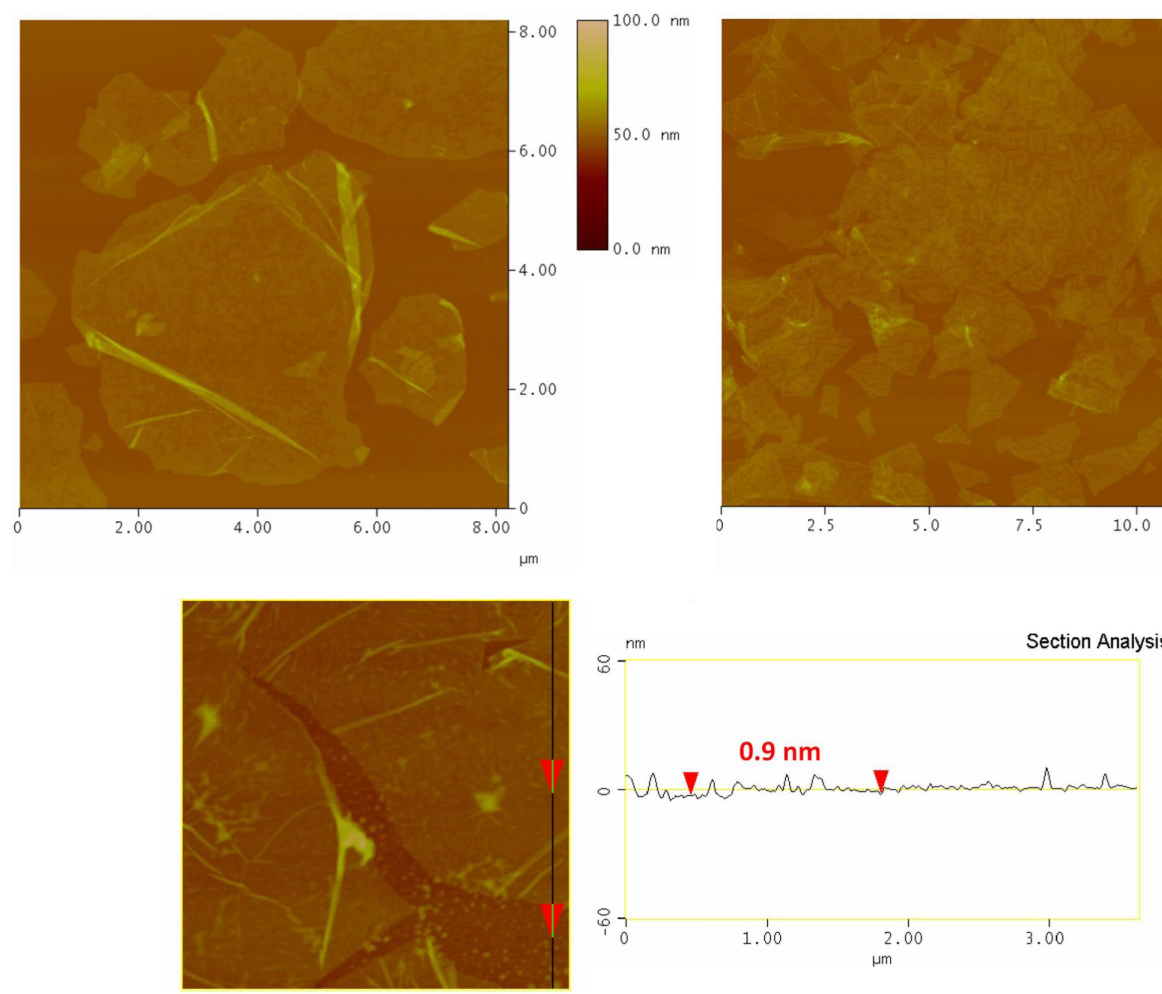

FIGURE 2 | Tapping mode AFM micrographs (and line profile) of a ODA-GO monolayer deposited with the Langmuir-Schaefer technique at a surface pressure of $20 \mathrm{mN} \mathrm{m}^{-1}$

Gomez-Navarro et al. (2007)] probably due to the presence of adsorbed water molecules.

CHARACTERIZATION OF HYBRID GRAPHENE/FULLERENE MULTILAYERS

The XRD pattern of an ODA-GO-ODA-C 60 hybrid multilayer (40 layers) is shown in Figure 3 in comparison with a ODA-GOODA hybrid multilayer (40 layers) that was synthesized under the

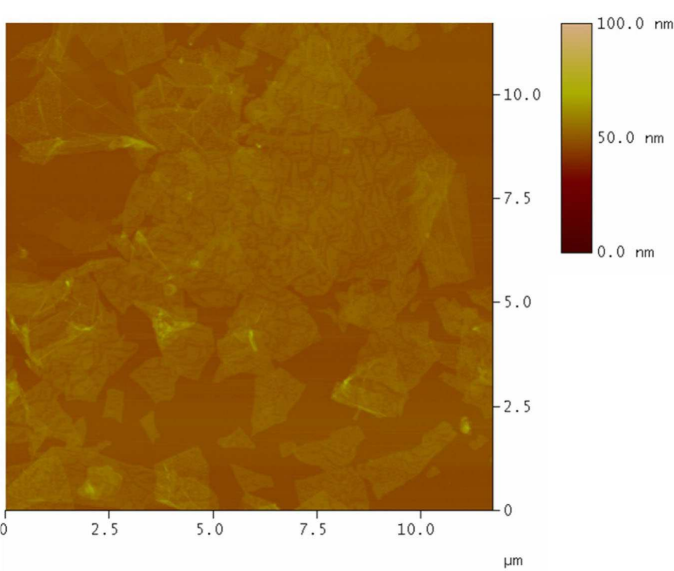

same experimental conditions. The ODA-GO-ODA- $\mathrm{C}_{60}$ hybrid multilayer shows a 001 diffraction peak at $2 \theta=2.2^{\circ}$, which corresponds to a $d_{001}$-spacing of $40 \AA$. This value is higher compared with the corresponding value of the ODA-GO-ODA multilayer $\left(d_{001}=37.6 \AA\right)$ testifying to the successful intercalation of the fullerene between the organo-graphene nanosheets. This increment does not correspond to the size of $\mathrm{C}_{60}(\sim 7 \AA)$ implying that 


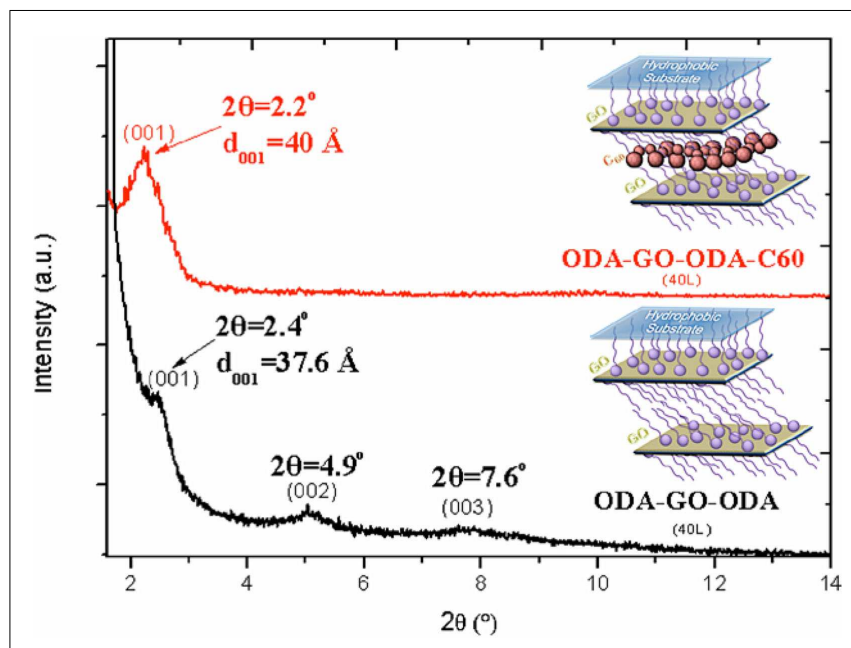

FIGURE 3 | X-ray diffraction patterns of ODA-GO-ODA- $C_{60}$ and ODA-GO-ODA hybrid multilayers (40 layers).

the fullerene molecules are accommodated between the double alkyl chains of the surfactant (see inset sketch) and not on top of it. Moreover, the absence of higher order ( $00 \mathrm{l})$ reflections in the XRD pattern of ODA-GO-ODA- $\mathrm{C}_{60}$ suggests that the GO layers are not stacked in perfect registry but have slipped sideways and are turbostratically disordered. A similar behavior has been observed upon intercalation of fullerene derivatives in aluminosilicate clay minerals (Gournis et al., 2006). This hypothesis is further supported by calculating the size of the coherently diffracting domains along the $c$ axis (also called mean crystalline thickness, $t$ ) that give rise to the 001 diffraction peak, given by the Debye-Scherrer equation, $t=K \lambda / \beta \cos \theta$, where $K$ is a constant near unity $(K=0.91), \lambda$ the $\mathrm{X}$-ray wavelength $(\lambda=1.5418 \AA), \theta$ the angular position of the first diffraction peak, and $\beta$ the full width at half maximum of the 001 peak expressed in radians. The crystalline thickness $(t)$ along $c$ axis of the ODA-GO-ODA- $\mathrm{C}_{60}$ and ODA-GO-ODA multilayers is found to be 114 and $153 \AA$, respectively. Dividing these values with the corresponding $d_{001}$-spacings, the number of stacked layers can be calculated to be $\sim 3$ for ODA-GO-ODA-C 60 and $\sim 4$ for ODA-GO-ODA, confirming the high degree of ordering of the produced multilayers.

Raman spectra of the ODA-GO-ODA-C 60 and the ODAGO-ODA multilayer samples are shown in Figure 4. Spectra are typical of GO materials, in that both exhibit the characteristic first-ordered G- and D-bands at around 1600 and $1350 \mathrm{~cm}^{-1}$, respectively. The $\mathrm{G}$-band is associated with $\mathrm{sp}^{2}$-hybridized carbon atoms and originates from the doubly degenerate zone center $E_{2 g}$ mode. The $\mathrm{D}$-band is correlated with $\mathrm{sp}^{3}$ hybridized carbon atoms as it requires a defect for its activation by double resonance, thus indicating the presence of lattice defects and distortions (Ferrari et al., 2006; Torrisi et al., 2012). The ratio of the D- to G-band intensities $\left(\mathrm{I}_{\mathrm{D}} / \mathrm{I}_{\mathrm{G}}\right)$ is indicative of the quality of the graphitic lattice. This ratio is equal to 1.06 for the ODA-GO-ODA- $\mathrm{C}_{60}$ multilayer and 1.04 for the ODA-GO-ODA multilayer, implying that fullerene intercalation into the interlayer space of the organo-graphene nanosheets does not influence the GO structure. In addition, the

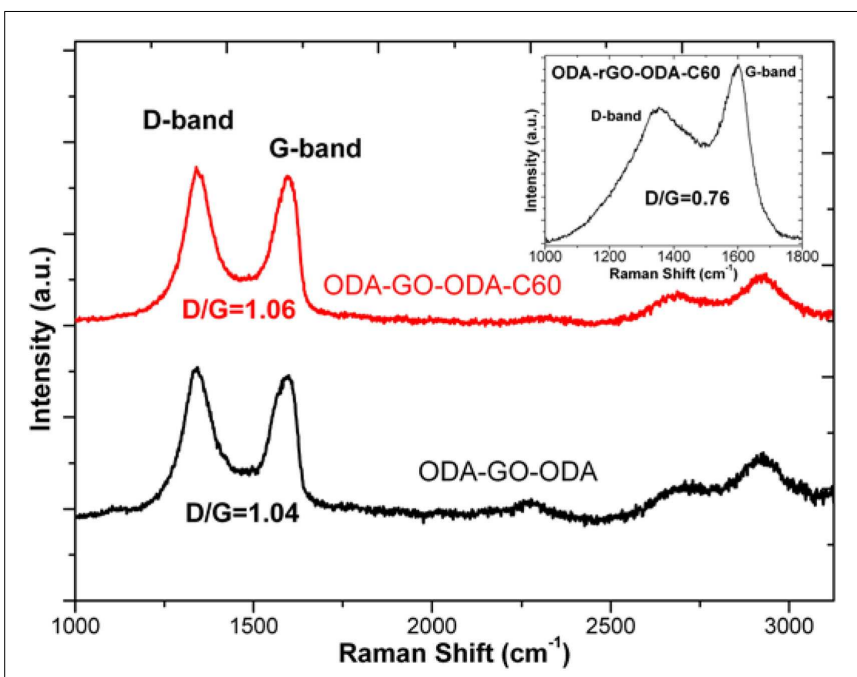

FIGURE 4 | Raman spectra of ODA-GO-ODA-C ${ }_{60}$ and ODA-GO-ODA hybrid multilayers (40 layers). Inset: Raman spectrum of the ODA-rGO-ODA- $\mathrm{C}_{60}$ hybrid multilayer after reduction and annealing.

shape of the two spectra in the $2 \mathrm{D}$ region is alike; both exhibit two broad peaks at $\sim 2700$ and $\sim 2930 \mathrm{~cm}^{-1}$. The low intensity $2700 \mathrm{~cm}^{-1}$ peak is attributed to the $2 \mathrm{D}$ (or else $\mathrm{G}^{\prime}$ ) vibrational mode, which is an overtone (second order) of the $\mathrm{D}$ peak. The second peak at $\sim 2930 \mathrm{~cm}^{-1}$ is assigned to the mode $\mathrm{D}+\mathrm{D}^{\prime}$, originating from the combination of phonons with different momenta, thus requiring defects for its activation; its intensity agrees with the defective nature of the $\mathrm{GO}$ lattice revealed by the high $\mathrm{I}_{\mathrm{D}} / \mathrm{I}_{\mathrm{G}}$ ratios of both samples (Ferrari et al., 2006; Martins Ferreira et al., 2010; Cançado et al., 2011; Torrisi et al., 2012). However, the typical pentagonal pinch mode $\left[\mathrm{A}_{\mathrm{g}}(2)\right]$ of $\mathrm{C}_{60}$ that is expected between 1440 and $1470 \mathrm{~cm}^{-1}$ (Spyrou et al., 2013) is not visible since it is superimposed on the broad D-band of GO. Moreover, upon reduction and annealing (see Figure 4 inset), the GO sheets show a noticeable decrease in the $\mathrm{D} / \mathrm{G}$ ratio from 1.06 to 0.76 . This observation suggests that while most of the oxygenated groups are removed (in the form of $\mathrm{CO}$ or $\mathrm{CO}_{2}$ ), the relative amount of disordered $\mathrm{sp}^{2}$-hybridized atoms is still high. The later could be explained either by the fact that amine molecules covalently bound to graphene survive the reduction and annealing procedures (contributing to an enhanced $\mathrm{sp}^{3}$ hybridization) or that vacancies produced during production of GO remain unchanged by the reduction process and ultimately define the intact graphene regions (Gomez-Navarro et al., 2007; Lomeda et al., 2008; Gengler et al., 2010).

The $\mathrm{C} 1 \mathrm{~s}$ core level X-ray photoelectron spectra of the graphene/fullerene hybrid multilayers before (ODA-GO-ODA$\left.\mathrm{C}_{60}\right)$ and after reduction and annealing (ODA-rGO-ODA- $\mathrm{C}_{60}$ ) in comparison with pristine $\mathrm{GO}$ and the organo-GO multilayers (ODA-GO-ODA) are shown in Figure 5. The spectrum of ODAGO-ODA displays four main contributions at 285.0, 286.1, 287.5, and $289.3 \mathrm{eV}$ corresponding to different carbon environments while for ODA-GO-ODA-C 60 an additional contribution appear at $290.5 \mathrm{eV}$. The peak at $285.0 \mathrm{eV}$ is attributed to the $\mathrm{C}-\mathrm{C}$ bonds 

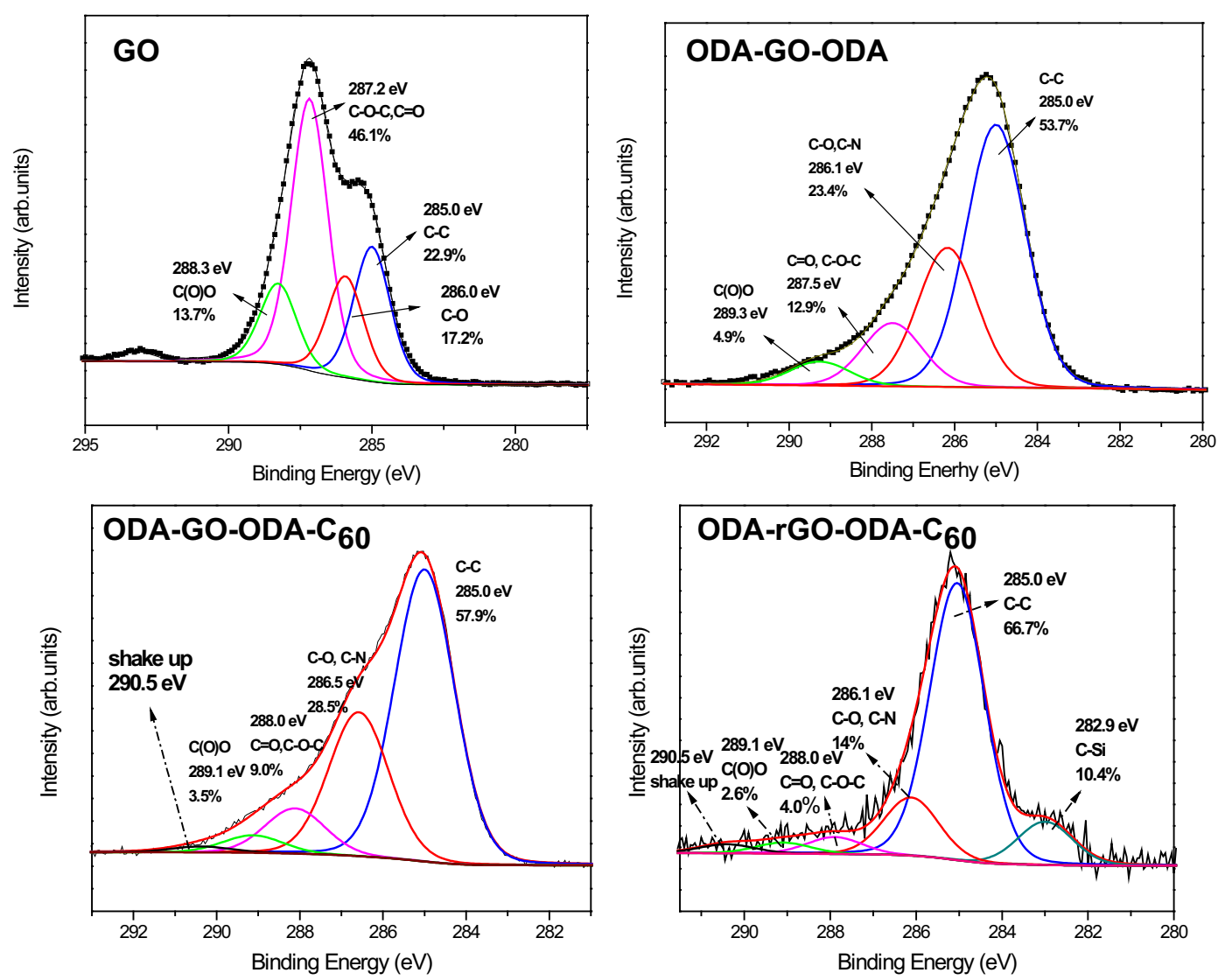

FIGURE 5 | X-ray photoelectron spectra of the $C$ 1s core level region of GO, ODA-GO-ODA and graphene/fullerene hybrid multilayers (40 layers) before (ODA-GO-ODA- $\mathrm{C}_{60}$ ) and after reduction and annealing (ODA-rGO-ODA- $\mathrm{C}_{60}$ ).

of the aromatic ring of $\mathrm{GO}$ as well the organic carbon-carbon groups of ODA attached to graphene and represents $53.7 \%$ of the total carbon 1s intensity of ODA-GO-ODA (Figure 5 left). This contribution is more intense in the case of ODA-GO-ODA- $\mathrm{C}_{60}$ (Figure 5 right) because in addition to photoemission signal due to the $\mathrm{C}-\mathrm{C}$ bonds of ODA and $\mathrm{GO}$ as also that from the $\mathrm{C}_{60}$ cage appears at this binding energy. The increased intensity of this peak to $57.9 \%$ of the total C1s signal testifies therefore to the successful incorporation of $\mathrm{C}_{60}$ into the layered structure. $\mathrm{C}-\mathrm{O}$ and $\mathrm{C}-\mathrm{N}$ both contribute to the photoelectron peak centered at $286.1 \mathrm{eV}$ for ODA-GO-ODA and $286.5 \mathrm{eV}$ for ODA-GO-ODA-C 60 ; in both spectra its intensity is higher than in the corresponding spectrum of GO starting material due to the chemical grafting of the amino groups of ODA with the epoxy groups of GO. Similarly, to the contribution at $287.5 \mathrm{eV}$ in the ODA-GO-ODA spectrum (at $288.0 \mathrm{eV}$ for ODA-GO-ODA-C 60 ) assigned to the epoxy groups of GO is decreased as compared to GO starting material, attesting that the epoxy groups have reacted with the amines via chemical grafting. The peak at $289.3 \mathrm{eV}$ in the ODA-GO-ODA spectrum (at $289.1 \mathrm{eV}$ for ODA-GO-ODA-C 60 ) is attributed to carboxyl groups created during the oxidation of GO. The additional peak at $290.5 \mathrm{eV}$ in the ODA-GO-ODA-C 60 spectrum is due to the C1s shake up features of $\mathrm{C}_{60}$ (Maxwell et al., 1994), resulting from $\pi-\pi^{*}$ transitions excited in the photoemission process, and therefore gives additional support to the presence of fullerenes in the hybrid multilayer (Felicissimo et al., 2009; Gengler et al., 2012a). Finally, upon reduction and subsequent annealing at $700^{\circ} \mathrm{C}$ the $\mathrm{C} 1 \mathrm{~s}$ spectral intensity due to oxygen-containing functional groups of graphite oxide (Figure 5) is significantly lower as compared to before the treatment, indicating a partial reconstruction of the graphene network expected to result in a better electrical conductivity (see below). It is noteworthy to mention that a new photoemission peak appears in the same spectrum at $282.9 \mathrm{eV}$; we attribute this peak to $\mathrm{C}-\mathrm{Si}$ bonds formed as a result of the annealing procedure. Finally, no N1s photoelectron peak was observed for both the ODA-rGO-ODA and ODA-rGO-ODA-C 60 samples, indicating that annealing did not cause any nitrogen doping of the graphene layers.

The sheet resistance measurements of the ODA-GO-ODA and ODA-GO-ODA- $\mathrm{C}_{60}$ multilayers gave values of about $15-20$ and $10 \mathrm{MOhm}$, respectively. These values were remarkably reduced to 20 and $4 \mathrm{kOhm}$, respectively, after the reduction and annealing treatment was applied in order to convert the deposited GO to graphene. These values are mean values of all measurements performed in different spots on both samples. By taking into account the thickness (as estimated from the AFM analysis) of 


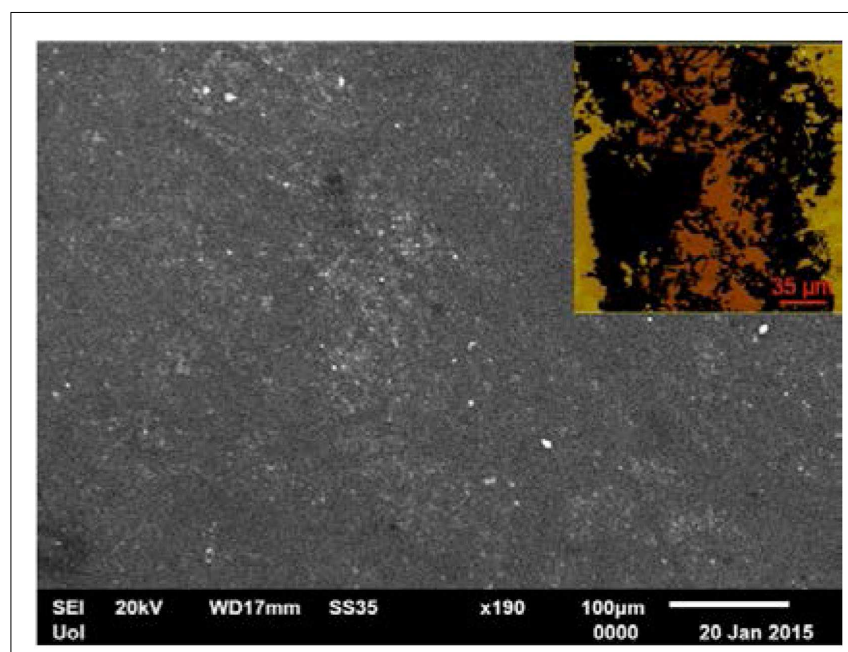

FIGURE 6 | Representative SEM image of ODA-rGO-ODA-C ${ }_{60}$. Inset: AFM micrograph of the same sample used for the surface roughness analysis

the films (70 nm for ODA-rGO-ODA and $90 \mathrm{~nm}$ for ODA-rGOODA- $\left.\mathrm{C}_{60}\right)$, the electrical conductivity of the reduced and annealed samples was found to amount to 714 and $2800 \mathrm{~S} \mathrm{~m}^{-1}$ without and with the $\mathrm{C}_{60}$, respectively. It is important to note that the films have a quite uniform and smooth surface as revealed by SEM measurements (Figure 6). The roughness analysis of the surface shown on the AFM micrograph in the inset of Figure 6, gave a mean roughness (RMS) of around $3 \mathrm{~nm}$. The poor electrical conductivity of both the ODA-GO-ODA and ODA-GO-ODA-C 60 mulitilayers is due to the presence of both ODA and the oxygen-containing groups decorating the GO sheets. However, the reduction and annealing steps improved substantially the electrical conductivity by removing effectively these moieties. The difference in sheet resistance between the two multilayers indicates a strong influence of the presence of $\mathrm{C}_{60}$. It is clear that the presence of $\mathrm{C}_{60}$ entrapped between graphene layers increases the electrical conductivity by an order of magnitude.

\section{CONCLUSION}

In conclusion, a highly controllable layer-by-layer synthetic approach for the production of a new class of hybrid carbonaceous structures was discussed. A 40-layer thick film consisting of organo-modified GO layers accommodating pure fullerene molecules $\left(\mathrm{C}_{60}\right)$ in the interlayer space was successfully fabricated by using a combination of the LS deposition method with two selfassembly steps from solution. Initially, the effectiveness of this method in terms of coverage, uniformity, and single-layer-level control of the assembly of the first organo-modified GO layer was confirmed by $\Pi-\alpha$ isotherms and AFM micrographs. For the hybrid, multilayer sample XRD measurements revealed the presence of the fullerene molecules within the interlayer space between the turbostratically layered organo-GO nanosheets and confirmed the high degree of ordering of the produced structure. The existence of fullerenes in the hybrid multilayer system was confirmed by XPS while Raman spectroscopy showed that the intercalation of the fullerene within the interlayer space of the organo-GO nanosheets did not affect the structure of GO itself. Finally, a considerably improvement (an order of magnitude) in the electrical conductivity of the hybrid multilayer, compared to the organo-graphene analog, was observed due to the presence of $\mathrm{C}_{60}$ entrapped between graphene layers. This graphene/fullerene hybrid material constitutes a novel hybrid system that could ideally be used in diverse applications such as transparent electrodes, thin film transistors, supercapacitors, or lubricants.

\section{ACKNOWLEDGMENTS}

This work was co-financed by the European Union (European Social Fund - ESF) and Greek national funds through the Operational Program "Education and Lifelong Learning" of the National Strategic Reference Framework (NSRF) - Research Funding Program: THALES. Investing in knowledge society through the European Social Fund. This work was also supported by the "Graphenebased electronics" research program of the Stichting voor Fundementeel Onderzoek der Materie (FOM), part of the Nederlandse Organisatie voor Wetenschappelijk Onderzoek (NWO).

\section{REFERENCES}

Bourlinos, A. B., Bakandritsos, A., Kouloumpis, A., Gournis, D., Krysmann, M., Giannelis, E. P., et al. (2012a). Gd(III)-doped carbon dots as a dual fluorescentMRI probe. J. Mater. Chem. 22, 23327-23330. doi:10.1039/c2jm35592b

Bourlinos, A. B., Georgakilas, V., Bakandritsos, A., Kouloumpis, A., Gournis, D., and Zboril, R. (2012b). Aqueous-dispersible fullerol-carbon nanotube hybrids. Mater. Lett. 82, 48-50. doi:10.1016/j.matlet.2012.05.026

Bourlinos, A. B., Gournis, D., Petridis, D., Szabo, T., Szeri, A., and Dekany, I. (2003). Graphite oxide: chemical reduction to graphite and surface modification with primary aliphatic amines and amino acids. Langmuir 19, 6050-6055. doi:10.1021/la026525h

Bourlinos, A. B., Karakassides, M. A., Kouloumpis, A., Gournis, D., Bakandritsos, A., Papagiannouli, I., et al. (2013). Synthesis, characterization and nonlinear optical response of organophilic carbon dots. Carbon N. Y. 61, 640-643. doi:10.1016/j.carbon.2013.05.017

Cançado, L. G., Jorio, A., Ferreira, E. H. M., Stavale, F., Achete, C. A., Capaz, R. B., et al. (2011). Quantifying defects in graphene via Raman spectroscopy at different excitation energies. Nano Lett. 11, 3190-3196. doi:10.1021/nl201432g

Chen, W., Li, S., Chen, C., and Yan, L. (2011). Self-assembly and embedding of nanoparticles by in situ reduced graphene for preparation of a 3D graphene/nanoparticle aerogel. Adv. Mater. 23, 5679-5683. doi:10.1002/adma. 201102838

Choi, B. G., Park, H., Park, T. J., Yang, M. H., Kim, J. S., Jang, S.-Y., et al. (2010). Solution chemistry of self-assembled graphene nanohybrids for high-performance flexible biosensors. ACS Nano 4, 2910-2918. doi:10.1021/nn100145x

Cote, L. J., Kim, F., and Huang, J. X. (2009). Langmuir-Blodgett assembly of graphite oxide single layers. J. Am. Chem. Soc. 131, 1043-1049. doi:10.1021/ja806262m

Dekany, I., Kruger-Grasser, R., and Weiss, A. (1998). Selective liquid sorption properties of hydrophobized graphite oxide nanostructures. Colloid Polym. Sci. 276, 570-576. doi:10.1007/s003960050283

Dreyer, D. R., Park, S., Bielawski, C. W., and Ruoff, R. S. (2010). The chemistry of graphene oxide. Chem. Soc. Rev. 39, 228-240. doi:10.1039/b917103g

Felicissimo, M. P., Jarzab, D., Gorgoi, M., Forster, M., Scherf, U., Scharber, M. C., et al. (2009). Determination of vertical phase separation in a polyfluorene copolymer: fullerene derivative solar cell blend by X-ray photoelectron spectroscopy. J. Mater. Chem. 19, 4899-4901. doi:10.1039/b906297a

Ferrari, A. C., Meyer, J. C., Scardaci, V., Casiraghi, C., Lazzeri, M., Mauri, F., et al. (2006). Raman spectrum of graphene and graphene layers. Phys. Rev. Lett. 97, 187401. doi:10.1103/PhysRevLett.97.187401

Gengler, R. Y. N. (2010). A Modified Langmuir Schaefer Method for the Creation of Functional Thin Films. Ph.D. thesis, University of Groningen, Groningen, 161.

Gengler, R. Y. N., Gournis, D., Aimon, A. H., Toma, L. M., and Rudolf, P. (2012a). The molecularly controlled synthesis of ordered bi-dimensional C60 arrays. Chem. Eur. J. 18, 7594-7600. doi:10.1002/chem.201103528 
Gengler, R. Y. N., Toma, L. M., Pardo, E., Lloret, F., Ke, X. X., Van Tendeloo, G., et al. (2012b). Prussian blue analogues of reduced dimensionality. Small 8, 2532-2540. doi:10.1002/smll.201200517

Gengler, R. Y. N., Veligura, A., Enotiadis, A., Diamanti, E. K., Gournis, D., Jozsa, C., et al. (2010). Large-yield preparation of high-electronic-quality graphene by a Langmuir-Schaefer approach. Small 6, 35-39. doi:10.1002/smll.200901120

Gomez-Navarro, C., Weitz, R. T., Bittner, A. M., Scolari, M., Mews, A., Burghard, M., et al. (2007). Electronic transport properties of individual chemically reduced graphene oxide sheets. Nano Lett. 7, 3499-3503. doi:10.1021/nl072090c

Gournis, D., Jankovic, L., Maccallini, E., Benne, D., Rudolf, P., Colomer, J. F., et al. (2006). Clay-fulleropyrrolidine nanocomposites. J. Am. Chem. Soc. 128, 6154-6163. doi:10.1021/ja0579661

Guldi, D. M., and Prato, M. (2000). Excited-state properties of C60 fullerene derivatives. Acc. Chem. Res. 33, 695-703. doi:10.1021/ar990144m

Hagerman, M. E., Salamone, S. J., Herbst, R. W., and Payeur, A. L. (2002). Tris (2,2' bipyridine)ruthenium(II) cations as photoprobes of clay tactoid architecture within hectorite and laponite films. Chem. Mater. 15, 443-450. doi:10.1021/ $\mathrm{cm} 0209160$

Iijima, S. (1991). Helical microtubules of graphitic carbon. Nature 354, 56-58. doi: $10.1038 / 354056 \mathrm{a} 0$

Junxiang, H., Sato, H., Umemura, Y., and Yamagishi, A. (2005). Sensing of molecular chirality on an electrode modified with a clay-metal complex hybrid film. J. Phys. Chem. B 109, 4679-4683. doi:10.1021/jp0451086

Kouloumpis, A., Zygouri, P., Dimos, K., and Gournis, D. (2014). "Layer-by-layer assembly of graphene-based hybrid materials," in Functionalization of Graphene, ed. V. Georgakilas (Weinheim: Wiley-VCH Verlag GmbH \& Co. KGaA), 359-400.

Lei, Z., Christov, N., and Zhao, X. S. (2011). Intercalation of mesoporous carbon spheres between reduced graphene oxide sheets for preparing high-rate supercapacitor electrodes. Energy Environ. Sci. 4, 1866-1873. doi:10.1039/clee01094h

Lomeda, J. R., Doyle, C. D., Kosynkin, D. V., Hwang, W. F., and Tour, J. M. (2008). Diazonium functionalization of surfactant-wrapped chemically converted graphene sheets. J. Am. Chem. Soc. 130, 16201-16206. doi:10.1021/ja806499w

Martins Ferreira, E. H., Moutinho, M. V. O., Stavale, F., Lucchese, M. M., Capaz, R. B., Achete, C. A., et al. (2010). Evolution of the Raman spectra from single-, few-, and many-layer graphene with increasing disorder. Phys. Rev. B 82, 125429. doi:10.1103/PhysRevB.82.125429

Maxwell, A. J., Bruhwiler, P. A., Nilsson, A., Martensson, N., and Rudolf, P. (1994). Photoemission, autoionization, and X-ray adsorption spectroscopy of ultrathinfilm C60 on Au(110). Phys. Rev. B 49, 10717-10725. doi:10.1103/PhysRevB.49. 10717

Michopoulos, A., Kouloumpis, A., Gournis, D., and Prodromidis, M. I. (2014). Performance of layer-by-layer deposited low dimensional building blocks of graphene-prussian blue onto graphite screen-printed electrodes as sensors for hydrogen peroxide. Electrochim. Acta 146, 477-484. doi:10.1016/j.electacta.2014. 09.031

Patil, A. J., Vickery, J. L., Scott, T. B., and Mann, S. (2009). Aqueous stabilization and self-assembly of graphene sheets into layered bio-nanocomposites using DNA. Adv. Mater. 21, 3159-3164. doi:10.1002/adma.200803633

Roh, K.-M., Jo, E.-H., Chang, H., Han, T. H., and Jang, H. D. (2014). High performance dye-sensitized solar cells using graphene modified fluorine-doped tin oxide glass by Langmuir-Blodgett technique. J. Solid State Chem. doi:10.1016/j. jssc.2014.04.022

Schniepp, H. C., Li, J. L., McAllister, M. J., Sai, H., Herrera-Alonso, M., Adamson, D. H., et al. (2006). Functionalized single graphene sheets derived from splitting graphite oxide. J. Phys. Chem. B 110, 8535-8539. doi:10.1021/jp060936f

Spyrou, K., Kang, L., Diamanti, E. K., Gengler, R. Y., Gournis, D., Prato, M., et al. (2013). A novel route towards high quality fullerene-pillared graphene. Carbon N. Y. 61, 313-320. doi:10.1016/j.carbon.2013.05.010

Staudenmaier, L. (1898). Verfahren zur Darstellung der Graphitsaure. Ber. Deut. Chem. Ges. 31, 1481. doi:10.1002/cber.18980310237

Stergiou, D. V., Diamanti, E. K., Gournis, D., and Prodromidis, M. I. (2010). Comparative study of different types of graphenes as electrocatalysts for ascorbic acid. Electrochem. Commun. 12, 1307-1309. doi:10.1016/j.elecom.2010.07.006
Toma, L. M., Gengler, R. Y. N., Prinsen, E. B., Gournis, D., and Rudolf, P. (2010). A Langmuir-Schaefer approach for the synthesis of highly ordered organoclay thin films. Phys. Chem. Chem. Phys. 12, 12188-12197. doi:10.1039/c0cp00286k

Torrisi, F., Hasan, T., Wu, W., Sun, Z., Lombardo, A., Kulmala, T. S., et al. (2012). Inkjet-printed graphene electronics. ACS Nano 6, 2992-3006. doi:10.1021/ nn2044609

Umemura, Y., Shinohara, E., and Schoonheydt, R. A. (2009). Preparation of Langmuir-Blodgett films of aligned sepiolite fibers and orientation of methylene blue molecules adsorbed on the film. Phys. Chem. Chem. Phys. 11, 9804-9810. doi: $10.1039 / \mathrm{b} 817635 \mathrm{c}$

Umemura, Y., Yamagishi, A., Schoonheydt, R., Persoons, A., and De Schryver, F. (2001). Fabrication of hybrid films of alkylammonium cations $(\mathrm{CnH} 2 \mathrm{n}+1 \mathrm{NH} 3+; \mathrm{n}=4-18)$ and a smectite clay by the Langmuir-Blodgett method. Langmuir 17, 449-455. doi:10.1021/la0011376

Umemura, Y., Yamagishi, A., Schoonheydt, R., Persoons, A., and De Schryver, F. (2002). Langmuir-Blodgett films of a clay mineral and ruthenium(II) complexes with a noncentrosymmetric structure. J. Am. Chem. Soc. 124, 992-997. doi:10.1021/ja016005t

Wang, D., Kou, R., Choi, D., Yang, Z., Nie, Z., Li, J., et al. (2010). Ternary selfassembly of ordered metal oxide-graphene nanocomposites for electrochemical energy storage. ACS Nano 4, 1587-1595. doi:10.1021/nn901819n

Yamamoto, T., Umemura, Y., Sato, O., and Einaga, Y. (2004a). Photomagnetic Co-Fe Prussian blue thin films fabricated by the modified Langmuir-Blodgett technique. Chem. Lett. 33, 500-501. doi:10.1246/cl.2004.500

Yamamoto, T., Umemura, Y., Sato, O., and Einaga, Y. (2004b). Photoswitchable magnetic films: Prussian blue intercalated in Langmuir-Blodgett films consisting of an amphiphilic azobenzene and a clay mineral. Chem. Mater. 16, 1195-1201. doi:10.1021/cm035223d

Yin, S., Niu, Z., and Chen, X. (2012). Assembly of graphene sheets into 3D macroscopic structures. Small 8, 2458-2463. doi:10.1002/smll.201102614

Yoshida, J., Saruwatari, K., Kameda, J., Sato, H., Yamagishi, A., Sun, L., et al. (2006). Electron transfer through clay monolayer films fabricated by the LangmuirBlodgett technique. Langmuir 22, 9591-9597. doi:10.1021/la061668f

Yu, D., and Dai, L. (2009). Self-assembled graphene/carbon nanotube hybrid films for supercapacitors. J. Phys. Chem. Lett. 1, 467-470. doi:10.1021/jz9003137

Zheng, Q., Ip, W. H., Lin, X., Yousefi, N., Yeung, K. K., Li, Z., et al. (2011a). Transparent conductive films consisting of ultralarge graphene sheets produced by Langmuir-Blodgett assembly. ACS Nano 5, 6039-6051. doi:10.1021/ nn2018683

Zheng, Q. B., Ip, W. H., Lin, X. Y., Yousefi, N., Yeung, K. K., Li, Z. G., et al. (2011b). Transparent conductive films consisting of ultra large graphene sheets produced by Langmuir-Blodgett assembly. ACS Nano 5, 6039-6051. doi:10.1021/ nn2018683

Conflict of Interest Statement: The authors declare that the research was conducted in the absence of any commercial or financial relationships that could be construed as a potential conflict of interest.

Received: 10 November 2014; accepted: 29 January 2015; published online: 13 February 2015.

Citation: Kouloumpis A, Spyrou K, Dimos K, Georgakilas V, Rudolf P and Gournis D (2015) A bottom-up approach for the synthesis of highly ordered fullerene-intercalated graphene hybrids. Front. Mater. 2:10. doi: 10.3389/fmats.2015.00010

This article was submitted to Carbon-Based Materials, a section of the journal Frontiers in Materials.

Copyright (c) 2015 Kouloumpis, Spyrou, Dimos, Georgakilas, Rudolf and Gournis. This is an open-access article distributed under the terms of the Creative Commons Attribution License (CC BY). The use, distribution or reproduction in other forums is permitted, provided the original author(s) or licensor are credited and that the original publication in this journal is cited, in accordance with accepted academic practice. No use, distribution or reproduction is permitted which does not comply with these terms. 